\title{
Submucosal Lipomas Causing Intussusception and Small Bowel Obstruction: A Case Report
}

\author{
Mohamed Ahmed ${ }^{1}$, Saba Habis ${ }^{2}$, Rasha Saeed ${ }^{1}$, Ahmed Mahmoud ${ }^{1}$, David Plurad ${ }^{1}$ \\ 1. Surgery, Riverside Community Hospital, Riverside, USA 2. Internal Medicine, Riverside Community Hospital, \\ Riverside, USA
}

Corresponding author: Mohamed Ahmed, maamsmd@yahoo.com

\begin{abstract}
Intussusception is a rare cause of bowel obstruction caused by both benign and malignant pathology. We are presenting the case of an elderly patient who had been diagnosed with irritable bowel syndrome for many years prior to presenting to us with ileocecal intussusception causing a small bowel

obstruction. Laparoscopic resection of the terminal ileum and cecum was performed. Pathology revealed multiple submucosal lipomas as the underlying cause.
\end{abstract}

Categories: Gastroenterology, General Surgery

Keywords: small bowel obstruction, submucosal lipoma, intussusception

\section{Introduction}

Intussusception is defined as the invagination of a proximal bowel segment into the lumen of an adjacent distal segment. It is the cause of $1 \%-5 \%$ of small bowel obstructions in adults [1]. The incidence is two to three cases per 1,000,000 per annum. The first reported case was made in 1674 by Dr. Paul Barbette of Amsterdam. The age of presentation is highly variable, ranging from the neonatal period to the seventh decade of life [2]. Intussusception in the ileocolic region is most commonly presented in children and is uncommon in adults [3]. Most patients with intestinal lipomatosis are asymptomatic; however, some present with subacute intermittent obstruction, colonic perforation, and rarely, intussusception [4]. The lead points for the intussusceptions are attributable to benign, malignant, or idiopathic causes [5].

\section{Case Presentation}

A 67-year-old Caucasian male, who been diagnosed for many years with irritable bowel syndrome, presented to our emergency room with a five-day history of abdominal pain, nausea, vomiting, and obstipation. The patient's past medical history also included hypertension and an appendectomy. His examination revealed a soft, distended abdomen. A computed tomography (CT) scan of the abdomen and pelvis was consistent with small bowel obstruction secondary to ileocecal intussusception (Figure 1).

Review began 11/12/2018

Review ended 11/28/2018

Published 12/05/2018

๑) Copyright 2018

Ahmed et al. This is an open access

article distributed under the terms of the Creative Commons Attribution License CC-BY 3.0., which permits unrestricted use, distribution, and reproduction in any medium, provided the original author and source are credited. 


\section{Cureus}

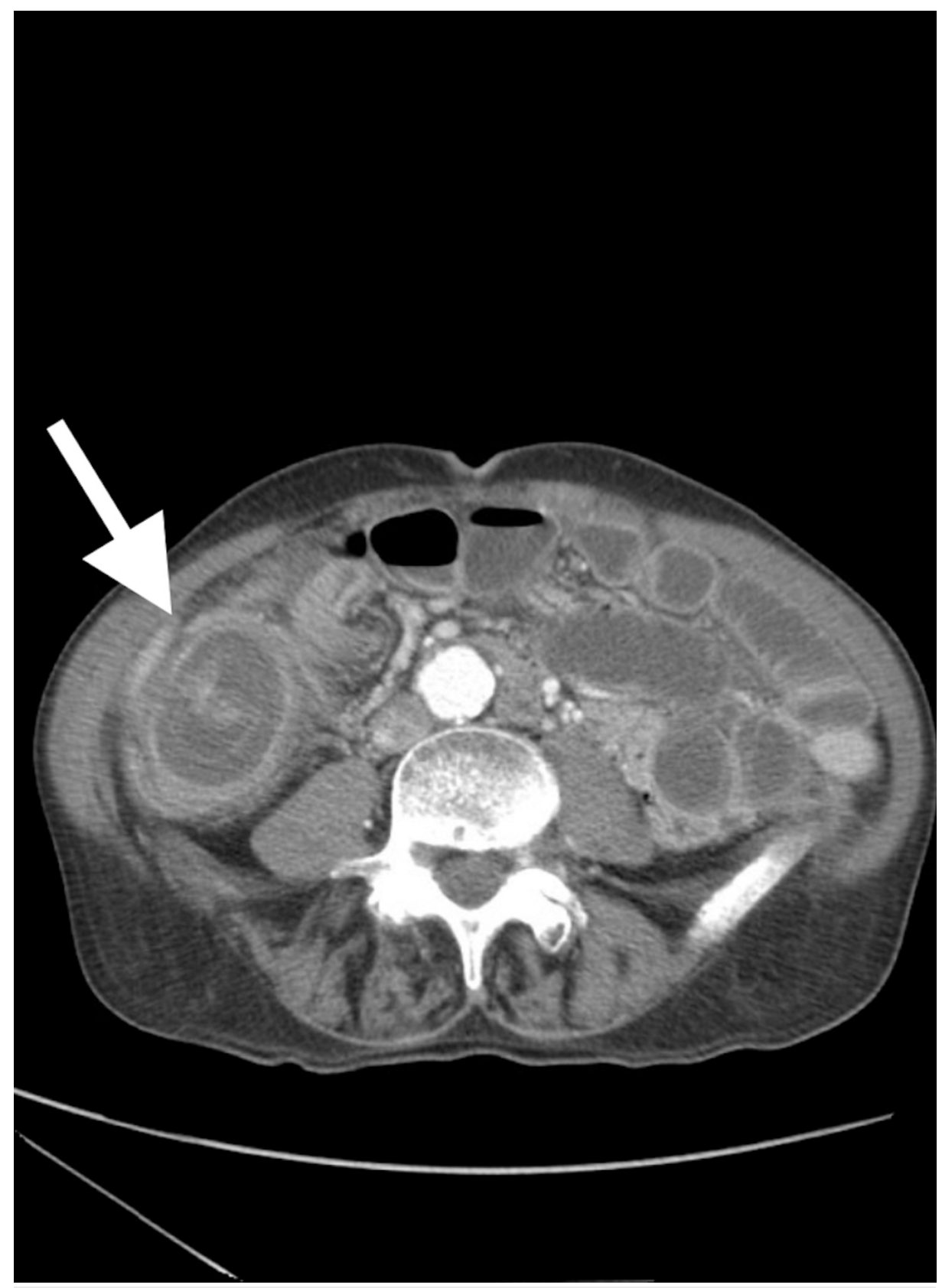

FIGURE 1: Axial computed tomography (CT) scan showing intussusception

He was admitted to the hospital, and a laparoscopic right hemicolectomy with resection of the terminal ileum and an extracorporeal side-to-side stapled ileocolic anastomosis was performed (Figure 2). The patient did well and was discharged from the hospital. 


\section{Cureus}

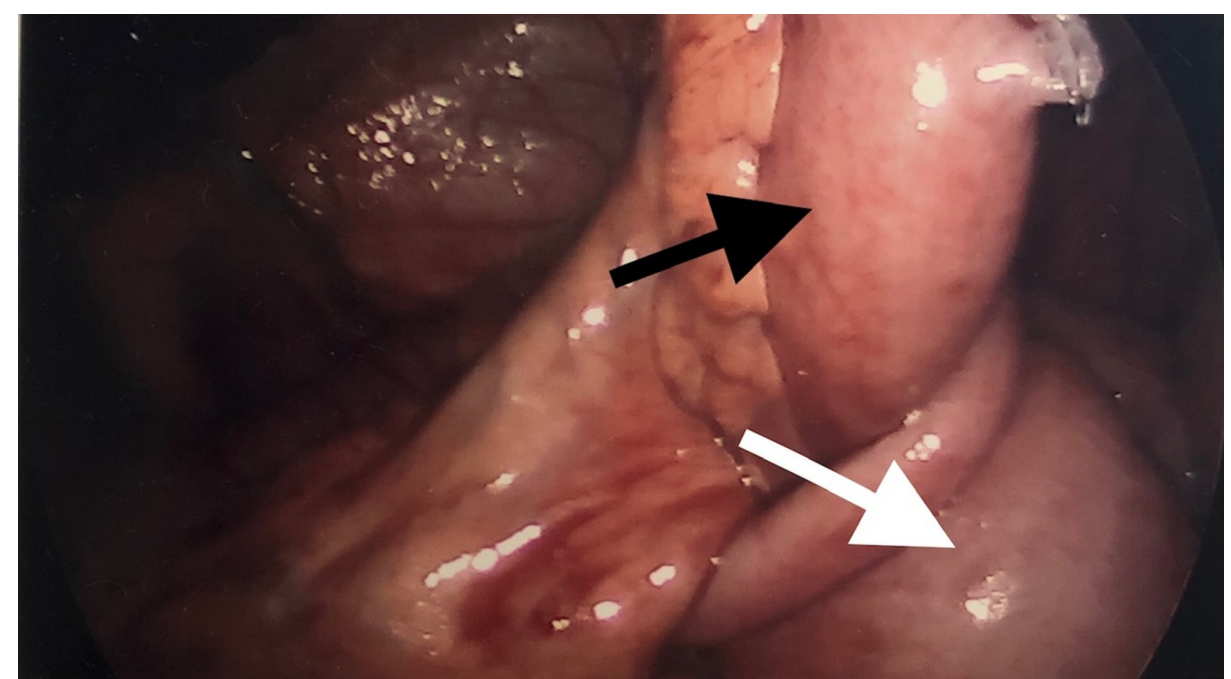

FIGURE 2: Laparoscopic view of the ileocecal intussusception

The terminal ileum (black arrow); the cecum (white arrow)

Gross pathology revealed two submucosal lipomas with an ischemic terminal ileum loop (Figure

3). Histopathological examination of the leading point indicated mature adipose tissue consistent with a lipoma (Figure 4). 


\section{Cureus}

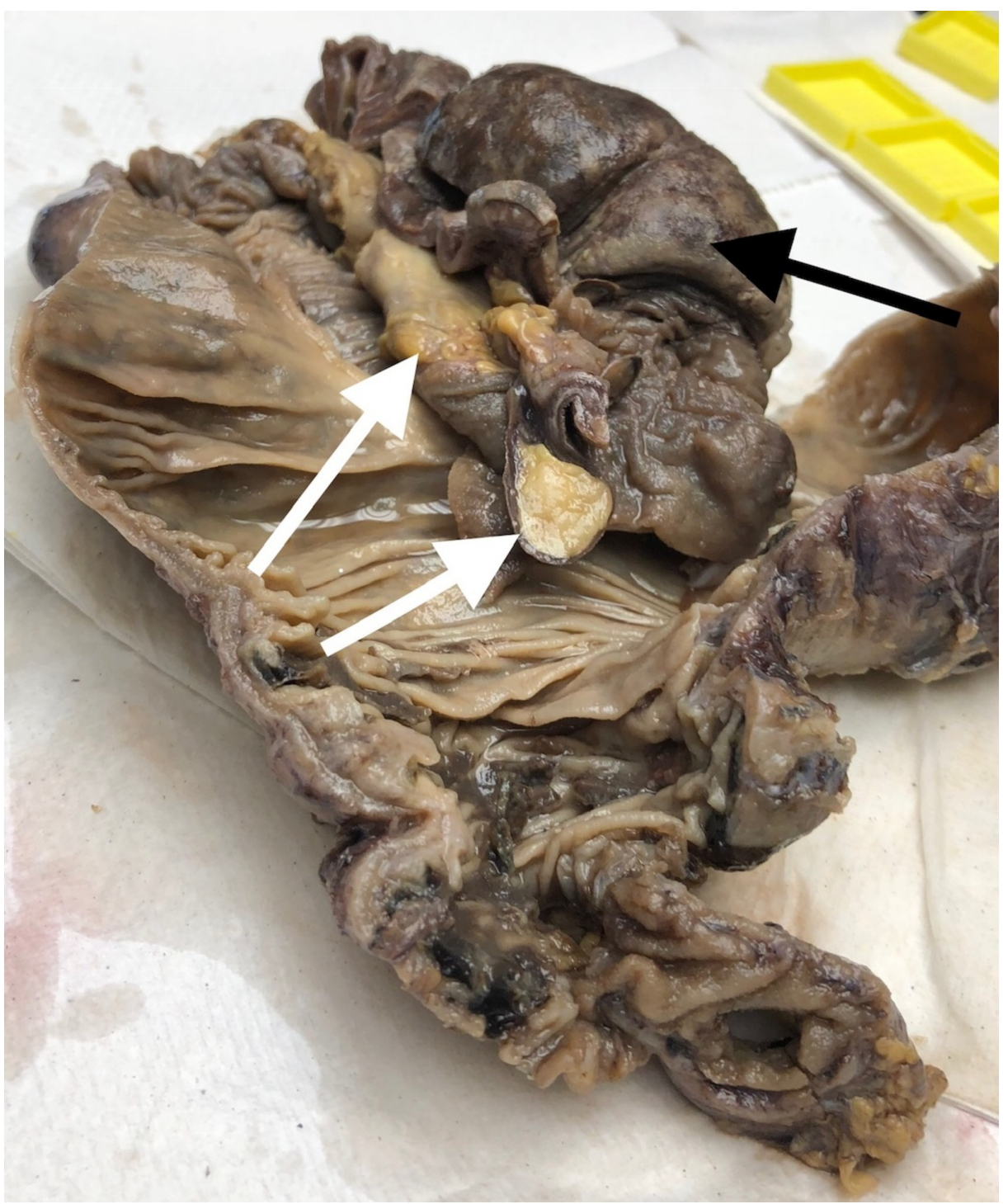

FIGURE 3: Gross pathology revealed two submucosal lipomas (white arrows)

Ischemic terminal ileum loop (black arrow) 


\section{Cureus}

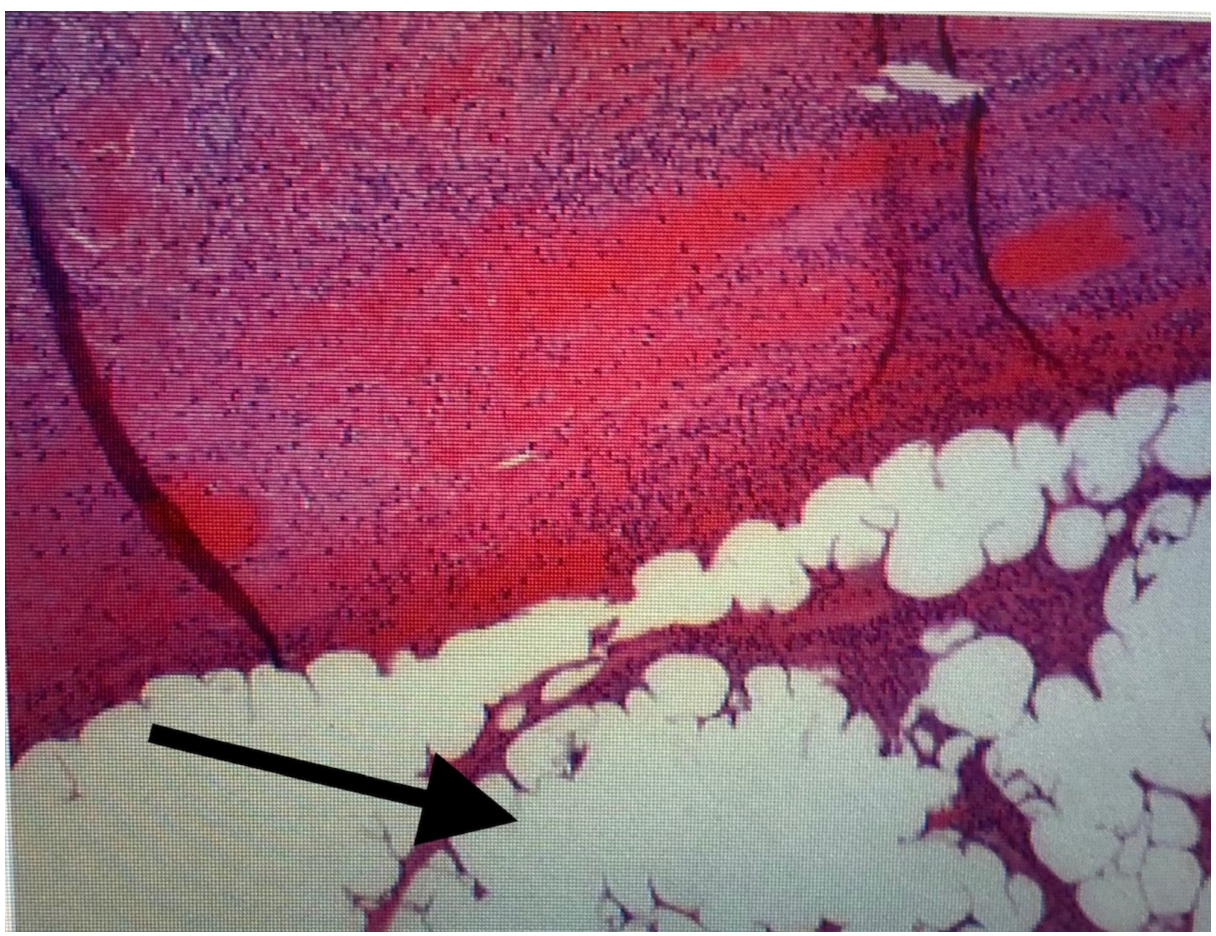

FIGURE 4: Histopathology revealed mature adipose tissue consistent with a lipoma (black arrow)

\section{Discussion}

The incidence of intussusception is two to three cases per 1,000,000 per annum. Intussusception is defined as the invagination of a proximal bowel segment into the lumen of an adjacent distal segment and being the cause of $1 \%-5 \%$ of small bowel obstructions in adults [6]. Intussusception in the ileocolic region most commonly presents in children and is uncommon in adults [3]. The lead points for the intussusceptions are attributable to benign, malignant, or idiopathic causes [6]. Most patients with intestinal lipomatosis are asymptomatic; however, some present with subacute intermittent obstruction, colonic perforation, and rarely, intussusception [7]. Repeated intussusceptions can happen in a patient with multiple submucosal lipomas [8]. A CT scan of the abdomen and pelvis has a $100 \%$ specificity and $87 \%$ sensitivity in adults [9]. While colo-colonic intussusception is predominately caused by malignancy ( $70 \%$ of cases), $70 \%$ of small intestine intussusceptions are caused by a benign pathology. Primary resection, open or laparoscopic, is the treatment of choice, especially in patients over 60 years old, because of the high incidence of malignancy [10].

\section{Conclusions}

Intussusception in adults is rare and is usually caused by an underlying tumor, most often malignant. Reduction in adults of an ischemic bowel and possible malignancy should not be attempted. Surgical resection either via laparoscopy or laparotomy is the best therapeutic option. A thorough gastrointestinal evaluation is also recommended prior to assigning the diagnoses of irritable bowel syndrome. In our case, the cause was multiple submucosal lipomas.

\section{Additional Information}

\section{Disclosures}

Human subjects: Consent was obtained by all participants in this study. Conflicts of interest: In compliance with the ICMJE uniform disclosure form, all authors declare the following: Payment/services info: All authors have declared that no financial support was received from any organization for the submitted work. Financial relationships: All authors have declared that they have no financial relationships at present or within the previous three years with any organizations that might have an interest in the submitted work. Other relationships: All authors have declared that there are no other relationships or activities that could appear to have influenced the submitted work.

\section{References}

1. Azar T, Berger DL: Adult intussusception. Ann Surg. 1997, 226:134-38. 10.1097/00000658-199708000-00003

2. Suárez Moreno RM, Hernández Ramírez DA, Madrazo Navarro M, Salazar Lozano CR, Martínez Gen R: 


\section{Cureus}

Multiple intestinal lipomatosis. Case report (Article in English, Spanish) . Cir Cir. 2010, 78:163-65.

3. Bodas A, Rivilla F, Maluenda C: Intestinal lipomatosis in a 10-year-old girl . Eur J Pediatr. 2008, 167:601-602. 10.1007/s00431-007-0530-z

4. Synder C, Cannon JA: Diffuse intestinal lipomatosis presenting as adult intussusception. World J Colorectal Surg. 2013, 3:14.

5. Reijnen HA, Joosten HJ, de Boer HH: Diagnosis and treatment of adult intussusception. Am J Surg. 1989, 158:25-28. 10.1016/0002-9610(89)90309-7

6. Felix EL, Cohen MH, Bernstein AD, Schwartz JH: Adult intussusception: case report of recurrent intussusception and review of the literature. Am J Surg. 1976, 131:758-61. 10.1016/0002-9610(76)90196-3

7. Kumar K, Noori MR, Patel KM, Yuen W, Bello C: Rare diagnosis of intestinal lipomatosis complicated by intussusception in an adult: a case report. Int J Surg Case Rep. 2017, 39:339-42. 10.1016/j.ijscr.2017.08.038

8. Yalamarthi S, Smith RC: Adult intussusception: case reports and review of literature. Postgrad Med J. 2005, 81:174-77. 10.1136/pgmj.2004.022749

9. Barbiera F, Cusmà S, Di Giacomo D, Finazzo M, Lo Casto A, Pardo S: Adult intestinal intussusception: comparison between CT features and surgical findings (Article in Italian). Radiol Med. 2001, 102:37-42.

10. Siow SL, Mahendran HA: A case series of adult intussusception managed laparoscopically . Surg Laparosc Endosc Percutan Tech. 2014, 24:327-31. 10.1097/SLE.0000000000000006 